\title{
Compartmentalized Neuronal Culture for Viral Transport Research
}

\author{
Yimin Wang ${ }^{1+}$, Shan Wang ${ }^{1+}$, Hongxia $\mathrm{Wu}^{2+}$, Xinxin Liu ${ }^{1}$, Jinyou Ma ${ }^{1}$, \\ Muhammad Akram Khan ${ }^{3}$, Aayesha Riaz ${ }^{4}$, Lei Wang ${ }^{1 *}$, Hua-ji Qiu ${ }^{2 *}$ and Yuan Sun ${ }^{2 *}$ \\ ${ }^{1}$ College of Animal Science and Veterinary Medicine, Henan Institute of Science and Technology, Xinxiang, China, ${ }^{2}$ State Key \\ Laboratory of Veterinary Biotechnology, Harbin Veterinary Research Institute, Chinese Academy of Agricultural Sciences, \\ Harbin, China, ${ }^{3}$ Department of Veterinary Pathology, Faculty of Veterinary and Animal Science, PMAS-Arid Agriculture \\ University, Rawalpindi, Pakistan, ${ }^{4}$ Department of Parasitology and Microbiology, Faculty of Veterinary and Animal Science, \\ PMAS-Arid Agriculture University, Rawalpindi, Pakistan
}

OPEN ACCESS

Edited by:

Akio Adachi,

Kansai Medical University, Japan

Reviewed by:

Hiroyuki Hioki,

Juntendo University, Japan Matthew Pendleton Taylor

Montana State University,

United States

*Correspondence:

Lei Wang

wlei_007@163.com

Hua-ji Qiu

qiuhuaji@caas.cn

Yuan Sun

sunyuan@caas.cn

${ }^{\dagger}$ These authors have contributed equally to this work

Specialty section: This article was submitted to

Virology,

a section of the journal Frontiers in Microbiology

Received: 30 March 2020 Accepted: 05 June 2020

Published: 15 July 2020

Citation:

Wang Y, Wang S, Wu H, Liu X, Ma J, Khan MA, Riaz A, Wang L, Qiu H and

Sun Y (2020) Compartmentalized

Neuronal Culture for Viral Transport

Research. Front. Microbiol. 11:1470.

doi: 10.3389/fmicb.2020.01470
Neuron-invading viruses usually enter via the peripheral organs/tissues of their mammalian hosts and are transported to the neurons. Virus trafficking is critical for transport or spread within the nervous system. Primary culture of neurons is a valuable and indispensable method for neurobiological research, allowing researchers to investigate basic mechanisms of diverse neuronal functions as well as retrograde and anterograde virus transport in neuronal axons. Primary ganglion sensory neurons from mice can be cultured in a compartmentalized culture device, which allows spatial fluidic separation of cell bodies and distal axons. These neurons serve as an important model for investigating the transport of viruses between the neuronal soma and distal axons. Alphaherpesviruses are fascinating and important human and animal pathogens, they replicate and establish lifelong latent infection in the peripheral nervous system, the mechanism of the viral transport along the axon is the key to understand the virus spread in the nervous system. In this review, we briefly introduce and evaluate the most frequently used compartmentalization tools in viral transport research, with particular emphasis on alphaherpesviruses.

Keywords: dorsal root ganglia (DRG) neurons, compartmentalized neuronal culture, campenot cell culture chambers, microfluidic neuronal culture, alpha herpesvirus, neuronal transport

\section{INTRODUCTION}

Studying viruses that infect the nervous system remains a challenge, especially determining how viruses spread within the nervous system. Most viruses begin infecting the nervous system from periphery tissue, often at epithelial or endothelial cell surfaces, invading the peripheral nervous system (PNS) or the central nervous system (CNS) along the axon of the neuron. The CNS is well-protected by complex multilayer barriers and immune responses. After virus infection, viruses invade the CNS via two main circuits: the blood supply and peripheral nerves (Swanson and McGavern, 2015). Neurons have long axons, and transport along the axon is necessary for the spread of some viruses (Koyuncu et al., 2013b; Taylor and Enquist, 2015; MacGibeny et al., 2018); therefore, studying the mechanism of virus transport along axons is useful for understanding virus spread in the nervous system. 
Isolated primary neurons such as dorsal root ganglia (DRG) neurons and superior cervical ganglia (SCG) (Howard et al., 2014) are widely used for experimental investigation of relevant questions in neurobiology and neurodevelopment and have served as an ideal model for understanding mechanisms of virus spread in the PNS (Tongtako et al., 2017). DRG including the neuronal cell bodies of sensory neurons and glial cells and are located in close proximity to the dorsal root of the spinal cord. DRG neurons are first-order neurons essential for the afferent transport of sensory information through long axons from the limbs and trunk into the CNS. DRG have pseudo-unipolarized morphology with well-defined cellular compartments, extremely long axons, and soma (Belmonte and Viana, 2008; Haberberger et al., 2019). The differentiation of sensory neurons from induced pluripotent stem cells (IPSCs) or embryonic stem cells (ESCs) which share the same properties with DRG neurons and also become ideal cell type to investigate the virus spread in the neurons (Kitazawa and Shimizu, 2011; Grigoryan et al., 2012; Lee et al., 2012; Rowe and Daley, 2019; Umehara et al., 2020). Conventional neuron culture methods do not allow manipulation and control of the culture environment between the soma and axon with enough spatial and temporal resolution to explore virus infection. Several new methods and techniques, consisting of compartmentalized neuronal culture tools, have therefore been developed for exploring virus spread in neurons through the axon. We summarize currently used methods in the field of compartmentalized platforms for understanding viral infection and transport in the nervous system.

\section{ALPHAHERPESVIRUSES}

Alphaherpesviruses $(\alpha \mathrm{HV})$ belong the family Herpesviridae comprising 41 species. Most are neurotropic viruses [such as herpes simplex virus (HSV), pseudorabies virus (PRV), and varicella-zoster virus (VZV)] and invade the nervous system when infecting their natural host. Herpesviruses infect epithelial cells, resulting in invasion of the PNS. However, the mechanism of invasion and transport of $\alpha \mathrm{HV}$ to neurons remains elusive.

HSV and VZV are prevalent and important human pathogens with seroprevalence of $\sim 80 \%$ in adults (Thaljeh et al., 2019). HSV-1 causes cold sores; it replicates in mucosal epithelia and is transmitted to nerve endings. Transmission is retrograde along the axon to the peripheral ganglia (Stults and Smith, 2019), where the virus can establish long-lasting latent infection; Reactivation of HSV can be triggered by a variety of internal or external stimuli to result in the production of infectious virus, and release of it to the mucosal epithelia by anterograde transport (Wilson and Mohr, 2012). VZV, causative agent of chickenpox, can also establish a latent infection in the nervous system (Mahalingam et al., 2019). Its reactivation in a dorsal root ganglion can lead to herpes zoster with debilitating chronic pain (Laemmle et al., 2019).

PRV is not a human pathogen, but its genome structure and function are similar to those of VZV and HSV (Szpara et al., 2011). Its natural hosts are pigs, but it can infect a broad range of animals. PRV is easy to culture in the laboratory, with rodent and chicken embryo models widely used to study mechanisms of PRV spread and replication in neurons (Pomeranz et al., 2005). All these features make PRV a perfect model for herpesvirus research. Bidirectional transport along the axon enables PRV invasion, replication, and spread in PNS neurons (Koyuncu et al., 2013a).

$\alpha \mathrm{HV}$ usually infect the mucosal surface of the host and then invade the nervous system by retrograde transport. Subsequently, the virus spreads to nerve endings to egress or enter the CNS by anterograde transport (Figure 1).

Understanding how viruses are transmitted from the mucosal surface to the nervous system can help avoid viral infection of neurons. It is therefore critical and necessary to understand the actively transport and spread of viruses in the neurons. By learning how viruses infect the nervous system and travel in neurons, we can mimic this process to study and treat related neurological diseases.

\section{COMPARTMENTALIZED NEURONAL CULTURE}

The most frequently used compartmentalized neuronal culture systems are the Campenot chamber and microfluidic cell culture. These tools enable manipulation and separation of the soma and axons.

\section{Campenot Chamber}

In 1977, the compartmentalized culture system known as the "Campenot chamber" was introduced by Campenot (1977). This three-chamber compartmentalized culture system was used to investigate nerve growth factor (NGF) control over the outgrowth of neurites from sympathetic neurons in vitro. It allows neurons to be seeded in one chamber and neurites to extend to other chambers, resulting in spatial separation of the neurons and axon. The fluidic separation of the chamber meets the requirements for NGF treatment of cell bodies or axons separately.

Briefly, silicone grease is used to seal the chamber to a tissue culture dish pre-coated with collagen and scratched to form parallel tracks (Figure 2A). This separates the three chambers while allowing axonal growth underneath the watertight silicone grease into a separate compartment (Pazyra-Murphy and Segal, 2008; Campenot et al., 2009). This method has been extensively used to study various neuronal functions, permitting analysis of RNA, protein, and lipids in both neuronal soma and distal axons separately during neuronal culture (Campenot, 1982, 1994; Karten et al., 2005). This has helped in studying neurotrophin signaling in the transport in the neurons (Wojaczynski et al., 2015; MacGibeny et al., 2018). Campenot chambers have been used by the Enquest laboratory to investigate viral transport (Kramer et al., 2012; Smith, 2012; Kratchmarov et al., 2013). The unique design of the Teflon ring makes it easy to infect the neurons distally or proximally. In this tri-chamber system, neuronal soma and their long axons are separately maintained in different 


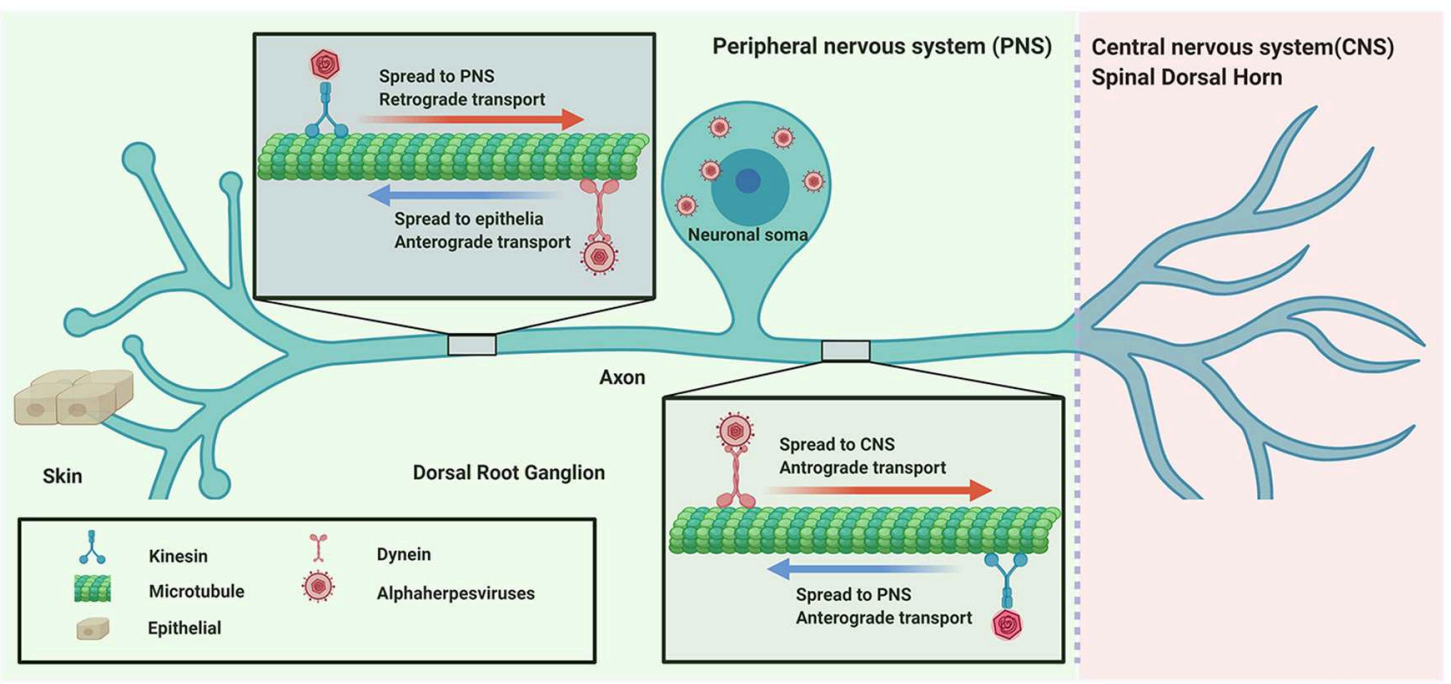

FIGURE 1 | Directional spread of neuroinvasion viruses (alphaherpesviruses) entering the nervous system.

chambers, allowing establishment of fluidic milieu isolated over each segment of the neuron, fluids in three chambers are separated and do not mix. Neuroinvasion viruses can therefore be inoculated into either the chamber containing the neuronal soma or the chamber with distal axons. If infection begins at the neuronal soma, viral particles will be transmitted anterogradely to distal axons along microtubules; in contrast, viral particles may display retrograde transport along microtubules to the soma from distal axons (Smith, 2012; Koyuncu et al., 2013b, 2015; Scherer et al., 2016; Song et al., 2016) (Figure 2A).

\section{Compartmentalized Microfluidic Culture}

Compartmentalized microfluidic technology has provided advanced platforms for neuroscience research over several decades (Zanto et al., 2011). It combines microfluidic, microfabrication, and surface micropatterning techniques to generate a neuronal culture system in a multicompartment device (Park et al., 2006). Application of microfluidics in the field of cell biology is becoming a powerful tool, due to its ability to precisely control, manipulate, and monitor sub-millimeter volume cellular culture environments (Taylor et al., 2005; Whitesides, 2006). Initially, microfluidic devices were designed for chemical and biomolecular analyses with higher sensitivity than traditional methods (Atencia and Beebe, 2005; Kim et al., 2018); more recently, they have been applied in cell biology (Dexter and Parker, 2009; Lo and Yao, 2015; Zhao et al., 2019).

Polydimethylsiloxane (PDMS) is the most popular material for fabricating microfluidic chambers using soft lithography techniques, with a plasma or non-plasma bonding method (Harris et al., 2007) used to seal the chamber to a glass substrate (Figure 2B). The chambers are divided by a barrier into which micron-size grooves are engraved (Taylor and Jeon, 2010), allowing neurites past the chambers (Park et al., 2006; Van Laar et al., 2019).

\section{Advantages and Disadvantages of Campenot Chambers and Compartmentalized Microfluidic Culture Systems}

Compartmentalized culture is becoming a valuable and powerful tool for neuroscience studies (Gross et al., 2007; Coluccio et al., 2019). It is difficult to manipulate and control the axonal growth of neurons in tissue culture plates with isotropic environment because establishment of neuronal polarity involves spontaneous and randomly orientated outgrowth. Compartmentalized culture systems confer a major advantage over single-chamber cell cultures by spatially separating the cellular compartment, the soma, and extension of the axon (Atencia and Beebe, 2005; Fantuzzo et al., 2019).

The Campenot chamber culture method has several disadvantages: (1) The device is difficult to assemble for the early users; (2) mechanical disturbance of the chamber may lead to leak owing to the silicon grease and disrupt the growth of neurites; (3) it is difficult to adapt the technique for sophisticated microscopy, owing to the structure of inner barrier and unoptical material, such as confocal microscopy and live cell imaging during the viral transport along the axon.

Microfluidics utilizes PDMS, which is easy to fabricate, low cost, and has optical properties compatible with highresolution microscopy, including confocal microcopy (Chiu et al., 2017). It is also non-toxic and permeable to gas, providing alternatively solution for compartmentalized neuronal cell culture (Park et al., 2006; Neto et al., 2016). it offers optical transparency, biocompatibility, and spatial and temporal control for manipulating cellular microenvironments.

The disadvantages of microfluidic devices are as following: (1) The PDMS surface can absorb small hydrophobic molecules (Wang et al., 2012); (2) limited number of axons entering the microfluidic grooves; (3) small volumes of media and 


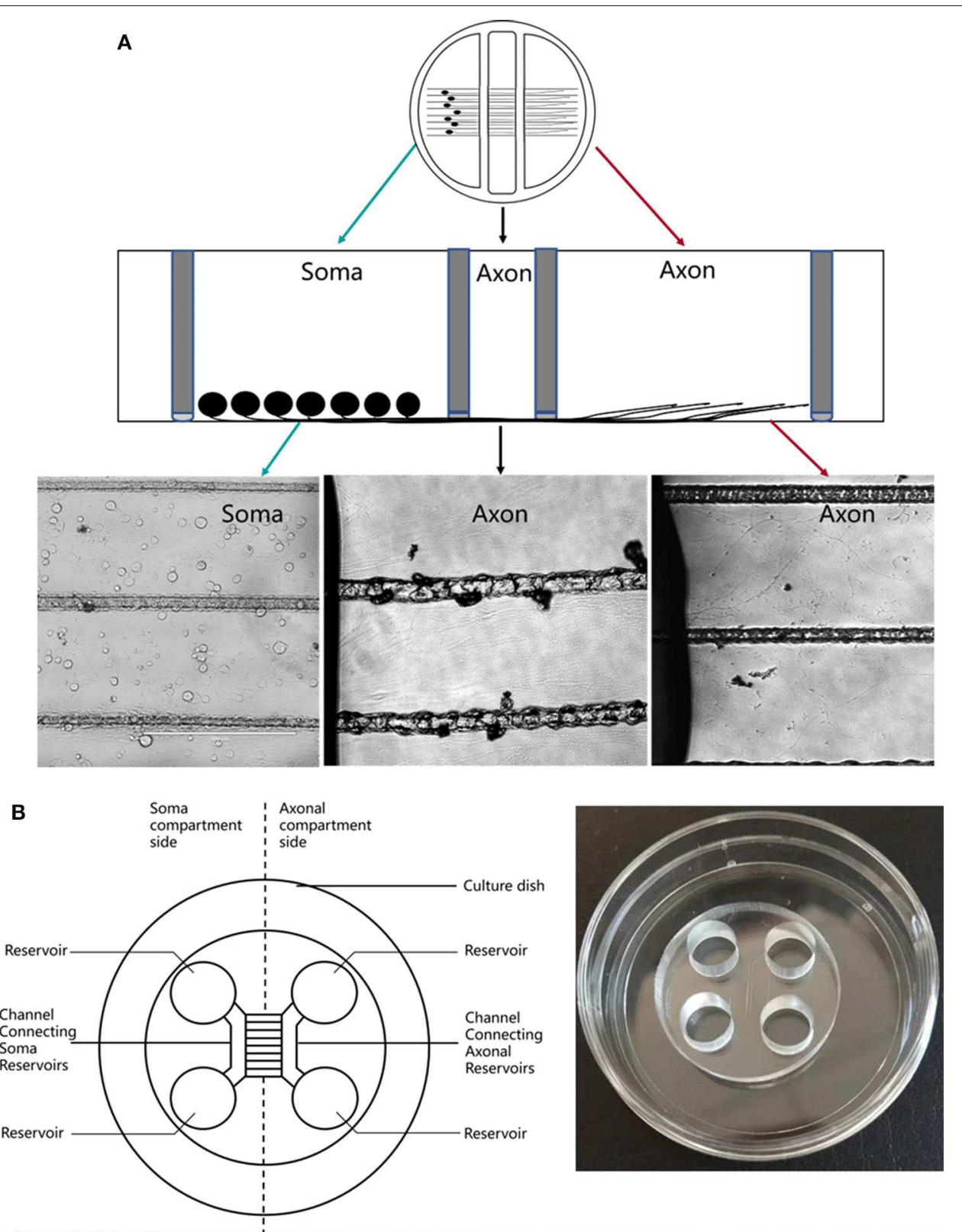

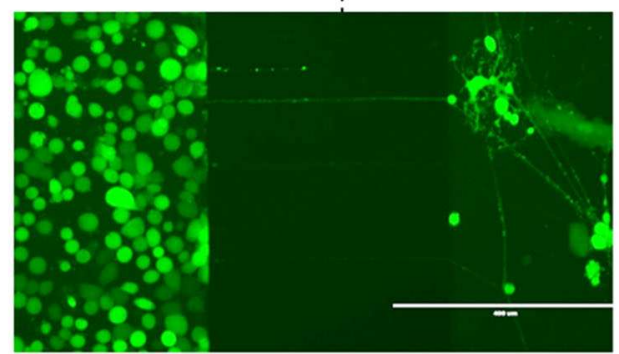

PK-15

Axon

Neuron

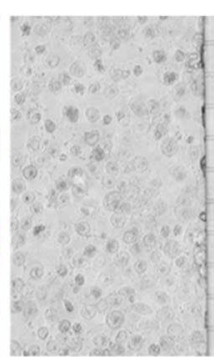

PK-15

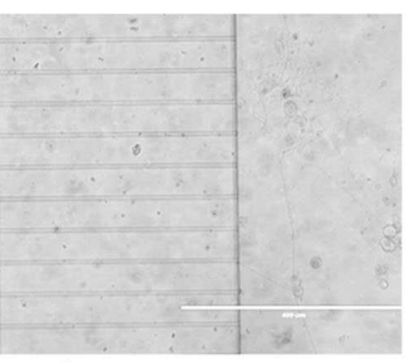

Axon
Neuron

FIGURE 2 | (A) Schematic diagram of a Campenot chamber. The neurons are placed in one chamber and extend their axons into the distal chamber. (B) Schematic diagram of microfluidic device.

constant requirements for fluidic flow to maintain diffusion of small molecules; (4) frequency of channel "blockage" during construction and reuse.
Most of these disadvantages of two methods can be surmounted by skilled operation or redesign the model for fabricating the microfluidic device (Park et al., 2009). All these 
properties make Campenot chamber and microfluidic culture are ideal and best tool for neuron growth and transport research.

There are still some other compartmentalized devices which are modified based on the "Campenot chamber" or microfluidics, such as two chambers device (De Regge et al., 2006; Hafezi et al., 2012) and redesigned microfluidic culture device (Park et al., 2009).

\section{APPLICATION OF COMPARTMENTALIZED DEVICES IN NEURONAL TRANSPORT MODELS IN VITRO}

Neuroinvasive viruses spread by infecting nerve terminals and transporting to the soma or other neurons, and by egressing from the soma to the nerve terminals utilizing cellular anterograde and retrograde transport.

Neurons are polarized cells with very long axons, which generally arise from the cell soma and synaptic contacts with other neurons or neurites. Axonal transport is an essential cellular process responsible for trafficking cargo such as mRNA granules, proteins, lipids, mitochondria, synaptic vesicles, autophagosomes, lysosomes, and organelles to their destinations along a polarized microtubule network using kinesin and dynein motor proteins (Terenzio et al., 2017; Sleigh et al., 2019). Anterograde transport is movement of newly biosynthesized proteins and lipids, and organelles from the soma to the synapse or cell membrane of distal axons utilizing the motor protein kinesin (Hirokawa and Tanaka, 2015). In the opposite direction, retrograde transport is involved in maintaining homeostasis by shuttling organelles and aging proteins from axon termini to the cell soma for degradation and recycling of components (Maday, 2016; Ferguson, 2018) utilizing the cytoplasmic protein dynein (Reck-Peterson et al., 2018).

Several studies have identified viruses that are transported along the axon. When $\alpha \mathrm{HV}$ enters into axons after membrane fusion, the capsid tegument protein VP1/2 recruits dynein motor proteins for retrograde transport to the cell soma (Zaichick et al., 2013); however, kinesin motor proteins can also bind purified capsid tegument complexes, suggesting that VP1/2 participates in multiple intracellular axonal transport processes during virus replication (Smith, 2012). During $\alpha \mathrm{HV}$ egress and spread, the viral membrane glycoprotein $\mathrm{gE} / \mathrm{gI}$ and US9 protein of PRV and HSV participate in anterograde transport to direct progeny

\section{REFERENCES}

Atencia, J., and Beebe, D. J. (2005). Controlled microfluidic interfaces. Nature 437, 648-655. doi: 10.1038/nature04163

Belmonte, C., and Viana, F. (2008). Molecular and cellular limits to somatosensory specificity. Mol. Pain 4:14. doi: 10.1186/1744-8069-4-14

Campenot, R. B. (1977). Local control of neurite development by nerve growth factor. Proc. Natl. Acad. Sci. U.S.A. 74, 4516-4519. doi: 10.1073/pnas.74.10.4516

Campenot, R. B. (1982). Development of sympathetic neurons in compartmentalized cultures. Dev. Biol. 93, 13-21. doi: 10.1016/00121606(82)90233-0 virions either into peripheral tissues or into the CNS (Smith, 2012; Kratchmarov et al., 2013). Interactions between viral proteins and cellular factors are complex, requiring further study using these techniques.

\section{CONCLUSIONS AND FUTURE PROSPECTS}

In conclusion, compartmentalized culture methods can be used to investigate viral transport. The most common and popular are the "Campenot chamber" and microfluidic culture system, and these methods provide the broadest picture of viral transport mechanisms.

Compartmentalized neuronal culture devices overcome the restrictions of conventional culture methods, making it easy and possible to understand the roles of viral proteins and neuronal proteins in axonal transport. This method can also be applied to co-culture epithelial or glial cells to study the role of these cells during the transport of the virus along the axon. By understanding how viruses move in axons, we can obtain more insight into the process of viral transmission and take measures to control it, especially the threat of latency of herpesviruses.

However, many questions still need to be addressed, such as how transport is coordinated by viral and cellular factors; how virion assembly affects the direction of transport; and how viral proteins and motor proteins are assembled.

\section{AUTHOR CONTRIBUTIONS}

YW and YS designed the concept of the review article. YW, SW, HW, and YS wrote the manuscript. XL, JM, LW, HQ, MK, and AR helped with revision of the manuscript. All authors read and approved the final manuscript.

\section{FUNDING}

This work was supported by Program for Innovative Research Team (in Science and Technology) in University of Henan Province (No. 18IRTSTHN019), the National Natural Science Foundation of China (No. 31702259), and the Key Specialized Research and Development Breakthrough program in Henan province (182102110347). 
investigations. Microelectron. Eng. 208, 14-28. doi: 10.1016/j.mee.2019. 01.004

De Regge, N., Nauwynck, H. J., Geenen, K., Krummenacher, C., Cohen, G. H., Eisenberg, R. J., et al. (2006). $\alpha$-Herpesvirus glycoprotein D interaction with sensory neurons triggers formation of varicosities that serve as virus exit sites. J. Cell Biol. 174, 267-275. doi: 10.1083/jcb.200510156

Dexter, J. P., and Parker, W. (2009). Parallel combinatorial chemical synthesis using single-layer poly(dimethylsiloxane) microfluidic devices. Biomicrofluidics 3, 1-9. doi: 10.1063/1.3230501

Fantuzzo, J. A., Hart, R. P., Zahn, J. D., and Pang, Z. P. (2019). Compartmentalized devices as tools for investigation of human brain network dynamics. Dev. Dyn. 248, 65-77. doi: 10.1002/dvdy.24665

Ferguson, S. M. (2018). Axonal transport and maturation of lysosomes. Curr. Opin. Neurobiol. 51, 45-51. doi: 10.1016/j.conb.2018.02.020

Grigoryan, S., Kinchington, P. R., Yang, I. H., Selariu, A., Zhu, H., Yee, M., et al. (2012). Retrograde axonal transport of VZV: kinetic studies in hESC-derived neurons. J. Neurovirol. 18, 462-470. doi: 10.1007/s13365-0120124-z

Gross, P. G., Kartalov, E. P., Scherer, A., and Weiner, L. P. (2007). Applications of microfluidics for neuronal studies. J. Neurol. Sci. 252, 135-143. doi: 10.1016/j.jns.2006.11.009

Haberberger, R. V., Barry, C., Dominguez, N., and Matusica, D. (2019). Human dorsal root ganglia. Front. Cell. Neurosci. 13:271. doi: 10.3389/fncel.2019.00271

Hafezi, W., Lorentzen, E. U., Eing, B. R., Müller, M., King, N. J. C., Klupp, B., et al. (2012). Entry of herpes simplex virus type 1 (HSV-1) into the distal axons of trigeminal neurons favors the onset of nonproductive, silent infection. PLoS Pathog. 8:e1002679. doi: 10.1371/journal.ppat.1002679

Harris, J., Lee, H., Vahidi, B., Tu, C., Cribbs, D., Cotman, C., et al. (2007). Nonplasma bonding of PDMS for inexpensive fabrication of microfluidic devices. J. Vis. Exp. 2007:e410. doi: 10.3791/410

Hirokawa, N., and Tanaka, Y. (2015). Kinesin superfamily proteins (KIFs): various functions and their relevance for important phenomena in life and diseases. Exp. Cell Res. 334, 16-25. doi: 10.1016/j.yexcr.2015.02.016

Howard, P. W., Wright, C. C., Howard, T., and Johnson, D. C. (2014). Herpes simplex virus gE/gI extracellular domains promote axonal transport and spread from neurons to epithelial cells. J. Virol. 88, 11178-11186. doi: 10.1128/jvi.01627-14

Karten, B., Hayashi, H., Campenot, R. B., Vance, D. E., and Vance, J. E. (2005). Neuronal models for studying lipid metabolism and transport. Methods 36, 117-128. doi: 10.1016/j.ymeth.2004.11.004

Kim, H., Lee, I. K., Taylor, K., Richters, K., Baek, D. H., Ryu, J. H., et al. (2018). Single-neuronal cell culture and monitoring platform using a fully transparent microfluidic DEP device. Sci. Rep. 8, 1-9. doi: 10.1038/s41598-018-31576-2

Kitazawa, A., and Shimizu, N. (2011). Differentiation of mouse induced pluripotent stem cells into neurons using conditioned medium of dorsal root ganglia. N. Biotechnol. 28, 326-333. doi: 10.1016/j.nbt.2011.03.011

Koyuncu, O. O., Hogue, I. B., and Enquist, L. W. (2013a). Virus infections in the nervous system. Cell Host Microbe 13, 379-393. doi: 10.1016/j.chom.2013.03.010

Koyuncu, O. O., Perlman, D. H., and Enquist, L. W. (2013b). Efficient retrograde transport of pseudorabies virus within neurons requires local protein synthesis in axons. Cell Host Microbe 13, 54-66. doi: 10.1016/j.chom.2012.10.021

Koyuncu, O. O., Song, R., Greco, T. M., Cristea, I. M., and Enquist, L. W. (2015). The number of alphaherpesvirus particles infecting axons and the axonal protein repertoire determines the outcome of neuronal infection. MBio 6, 1-12. doi: $10.1128 / \mathrm{mBio} .00276-15$

Kramer, T., Greco, T. M., Taylor, M. P., Ambrosini, A. E., Cristea, I. M., and Enquist, L. W. (2012). Kinesin-3 mediates axonal sorting and directional transport of alphaherpesvirus particles in neurons. Cell Host Microbe 12, 806-814. doi: 10.1016/j.chom.2012.10.013

Kratchmarov, R., Taylor, M. P., and Enquist, L. W. (2013). Role of Us9 phosphorylation in axonal sorting and anterograde transport of pseudorabies virus. PLoS ONE 8:e58776. doi: 10.1371/journal.pone.0058776

Laemmle, L., Goldstein, R. S., and Kinchington, P. R. (2019). Modeling varicella zoster virus persistence and reactivation - Closer to resolving a perplexing persistent state. Front. Microbiol. 10:1634. doi: 10.3389/fmicb.2019.01634

Lee, K. S., Zhou, W., Scott-McKean, J. J., Emmerling, K. L., Cai, G., yun, Krah, D. L., et al. (2012). Human sensory neurons derived from induced pluripotent stem cells support varicella-zoster virus infection. PLoS ONE 7:e53010. doi: 10.1371/journal.pone.0053010

Lo, S. J., and Yao, D. J. (2015). Get to understand more from single-cells: current studies of microfluidic-based techniques for single-cell analysis. Int. J. Mol. Sci. 16, 16763-16777. doi: 10.3390/ijms160816763

MacGibeny, M. A., Koyuncu, O. O., Wirblich, C., Schnell, M. J., and Enquist, L. W. (2018). Retrograde axonal transport of rabies virus is unaffected by interferon treatment but blocked by emetine locally in axons. PLoS Pathog. 14:e1007188. doi: 10.1371/journal.ppat.1007188

Maday, S. (2016). Mechanisms of neuronal homeostasis: autophagy in the axon. Brain Res. 1649, 143-150. doi: 10.1016/j.brainres.2016.03.047

Mahalingam, R., Gershon, A., Gershon, M., Cohen, J. I., Arvin, A., Zerboni, L., et al. (2019). Current in vivo models of varicella-zoster virus neurotropism. Viruses 11, 1-25. doi: 10.3390/v11060502

Neto, E., Leitão, L., Sousa, D. M., Alves, C. J., Alencastre, I. S., Aguiar, P., et al. (2016). Compartmentalized microfluidic platforms: the unrivaled breakthrough of in vitro tools for neurobiological research. J. Neurosci. 36, 11573-11584. doi: 10.1523/JNEUROSCI.1748-16.2016

Park, J. W., Kim, H. J., Byun, J. H., Ryu, H. R., and Jeon, N. L. (2009). Novel microfluidic platform for culturing neurons: culturing and biochemical analysis of neuronal components. Biotechnol. J. 4, 1573-1577. doi: 10.1002/biot.200900159

Park, J. W., Vahidi, B., Taylor, A. M., Rhee, S. W., and Jeon, N. L. (2006). Microfluidic culture platform for neuroscience research. Nat. Protoc. 1, 2128-2136. doi: 10.1038/nprot.2006.316

Pazyra-Murphy, M. F., and Segal, R. A. (2008). Preparation and maintenance of dorsal root ganglia neurons in compartmented cultures. J. Vis. Exp. 2008:e951. doi: $10.3791 / 951$

Pomeranz, L. E., Reynolds, A. E., and Hengartner, C. J. (2005). Molecular biology of pseudorabies virus: impact on neurovirology and veterinary medicine. Microbiol. Mol. Biol. Rev. 69, 462-500. doi: 10.1128/mmbr.69.3.462-500.2005

Reck-Peterson, S. L., Redwine, W. B., Vale, R. D., and Carter, A. P. (2018). The cytoplasmic dynein transport machinery and its many cargoes. Nat. Rev. Mol. Cell Biol. 19, 382-398. doi: 10.1038/s41580-018-0004-3

Rowe, R. G., and Daley, G. Q. (2019). Induced pluripotent stem cells in disease modelling and drug discovery. Nat. Rev. Genet. 20, 377-388. doi: 10.1038/s41576-019-0100-Z

Scherer, J., Yaffe, Z. A., Vershinin, M., and Enquist, L. W. (2016). Dual-color herpesvirus capsids discriminate inoculum from progeny and reveal axonal transport dynamics. J. Virol. 90, 9997-10006. doi: 10.1128/jvi.01122-16

Sleigh, J. N., Rossor, A. M., Fellows, A. D., Tosolini, A. P., and Schiavo, G. (2019). Axonal transport and neurological disease. Nat. Rev. Neurol. 15, 691-703. doi: $10.1038 / s 41582-019-0257-2$

Smith, G. (2012). Herpesvirus transport to the nervous system and back again. Аnnu. Rev. Microbiol. 66, 153-176. doi: 10.1146/annurev-micro092611-150051

Song, R., Koyuncu, O. O., Greco, T. M., Diner, B. A., Cristea, I. M., and Enquist, L. W. (2016). Two modes of the axonal interferon response limit alphaherpesvirus neuroinvasion. MBio 7:e02145-15. doi: 10.1128/mBio.02145-15

Stults, A. M., and Smith, G. A. (2019). The herpes simplex virus type I deamidase enhances propagation but is dispensable for retrograde axonal transport into the nervous system. J. Virol. 93:e01172-19. doi: 10.1128/jvi.01172-19

Swanson, P. A. III., and McGavern, D. B. (2015). Viral diseases of the central nervous system. Curr. Opin. Virol. 11, 44-54. doi: 10.1016/j.coviro.2014. 12.009

Szpara, M. L., Tafuri, Y. R., Parsons, L., Shamim, S. R., Verstrepen, K. J., Legendre, M., et al. (2011). A wide extent of inter-strain diversity in virulent and vaccine strains of Alphaherpesviruses. PLoS Pathog. 7:e1002282. doi: 10.1371/journal.ppat.1002282

Taylor, A. M., Blurton-Jones, M., Rhee, S. W., Cribbs, D. H., Cotman, C. W., and Jeon, N. L. (2005). A microfluidic culture platform for CNS axonal injury, regeneration and transport. Nat. Methods 2, 599-605. doi: 10.1038/ nmeth777

Taylor, A. M., and Jeon, N. L. (2010). Micro-scale and microfluidic devices for neurobiology. Curr. Opin. Neurobiol. 20, 640-647. doi: 10.1016/j.conb.2010.07.011

Taylor, M. P., and Enquist, L. W. (2015). Axonal spread of neuroinvasive viral infections. Trends Microbiol. 23, 283-288. doi: 10.1016/j.tim.2015.01.002 
Terenzio, M., Schiavo, G., and Fainzilber, M. (2017). Compartmentalized signaling in neurons: from cell biology to neuroscience. Neuron 96, 667-679. doi: 10.1016/j.neuron.2017.10.015

Thaljeh, L. F., Rothschild, J. A., Naderi, M., Coghill, L. M., Brown, J. M., and Brylinski, M. (2019). Hinge region in DNA packaging terminase pUL15 of herpes simplex virus: a potential allosteric target for antiviral drugs. Biomolecules 9, 1-20. doi: 10.3390/biom9100603

Tongtako, W., Lehmbecker, A., Wang, Y., Hahn, K., Baumgärtner, W., and Gerhauser, I. (2017). Canine dorsal root ganglia satellite glial cells represent an exceptional cell population with astrocytic and oligodendrocytic properties. Sci. Rep. 7:13915. doi: 10.1038/s41598-017-14246-7

Umehara, Y., Toyama, S., Tominaga, M., Matsuda, H., Takahashi, N., Kamata, Y., et al. (2020). Robust induction of neural crest cells to derive peripheral sensory neurons from human induced pluripotent stem cells. Sci. Rep. 10, 1-10. doi: 10.1038/s41598-020-60036-Z

Van Laar, V., Arnold, B., and Berman, S. (2019). Primary embryonic rat cortical neuronal culture and chronic rotenone treatment in microfluidic culture devices. Bio Protoc. 9:e3192. doi: 10.21769/bioprotoc.3192

Wang, J. D., Douville, N. J., Takayama, S., and Elsayed, M. (2012). Quantitative analysis of molecular absorption into PDMS microfluidic channels. Ann. Biomed. Eng. 40, 1862-1873. doi: 10.1007/s10439-0120562-z

Whitesides, G. M. (2006). The origins and the future of microfluidics. Nature 442, 368-373. doi: 10.1038/nature05058

Wilson, A. C., and Mohr, I. (2012). A cultured affair: HSV latency and reactivation in neurons. Trends Microbiol. 20, 604-611. doi: 10.1016/j.tim.2012. 08.005
Wojaczynski, G. J., Engel, E. A., Steren, K. E., Enquist, L. W., and Patrick Card, J. (2015). The neuroinvasive profiles of H129 (herpes simplex virus type 1) recombinants with putative anterograde-only transneuronal spread properties. Brain Struct. Funct. 220, 1395-1420. doi: 10.1007/s00429-014-0733-9

Zaichick, S. V., Bohannon, K. P., Hughes, A., Sollars, P. J., Pickard, G. E., and Smith, G. A. (2013). The herpesvirus VP1/2 protein is an effector of dyneinmediated capsid transport and neuroinvasion. Cell Host Microbe 13, 193-203. doi: 10.1016/j.chom.2013.01.009

Zanto, T. P., Hennigan, K., Östberg, M., Clapp, W. C., and Gazzaley, A. (2011). Predictive knowledge of stimulus relevance does not influence top-down suppression of irrelevant information in older adults. Cortex 46, 564-574. doi: 10.1016/j.cortex.2009.08.003

Zhao, Q., Cui, H., Wang, Y., and Du, X. (2019). Microfluidic platforms toward rational material fabrication for biomedical applications. Small 16, 1-22. doi: $10.1002 / \mathrm{smll} .201903798$

Conflict of Interest: The authors declare that the research was conducted in the absence of any commercial or financial relationships that could be construed as a potential conflict of interest.

Copyright (c) 2020 Wang, Wang, Wu, Liu, Ma, Khan, Riaz, Wang, Qiu and Sun. This is an open-access article distributed under the terms of the Creative Commons Attribution License (CC BY). The use, distribution or reproduction in other forums is permitted, provided the original author(s) and the copyright owner(s) are credited and that the original publication in this journal is cited, in accordance with accepted academic practice. No use, distribution or reproduction is permitted which does not comply with these terms. 